\title{
2
}

\section{Overcoming Obstacles in Applying SWMM to Large-Scale Watersheds}

Seung Ah Byun, James T. Smullen, Mark Maimone, Robert E. Dickinson and Christopher S. Crockett

The RUNOFF module of the U.S. EPA's Storm Water Management Model (SWMM) was used to simulate the watershed hydrology and water quality contaminant loadings for the Schuylkill River Basin. The Schuylkill River is over $130 \mathrm{mi}$. $(210 \mathrm{~km})$ long, includes over 180 higher-order tributaries draining more than 2,000 square mi. (5,100 square $\mathrm{km}$ ). For the model of this basin, simulated runoff loadings were accumulated at major junctures, or inlet points, for up to 14 land use categories in each of the 356 sub-watersheds, resulting in over 3,000 RUNOFF module sub-basins. This allows results to be summarized by land use, by model basin, by accumulated groupings of sub-watersheds, and for the entire watershed study area. Continuous SWMM was applied using a 15-min simulation time step, with full implementation of the snowmelt and groundwater subroutines, for execution periods of $30 \mathrm{y}$, to generate estimates of seasonal and annual watershed discharge and loadings.

We believe this to be one of the largest applications of SWMM RUNOFF in terms of the combination of the size of the drainage area, the number of subbasins, and the number of simulation time steps. The use of SWMM at this scale uncovered numerous limitations of the model requiring either modifications to the SWMM code or the implementation of functional work-arounds. For example, array bounds set for the input and simulation data required modifications to the SWMM code expanding the limits. Also, during the calibration of the model, SWMM did not allow retrieval of daily flows at select inlet points,

Byun, S.A., J. Smullen, M. Maimone, R.E. Dickinson and C.S. Crockett. 2003. "Overcoming Obstacles in Applying SWMM to Large-Scale Watersheds." Journal of Water Management Modeling R215-02. doi: 10.14796/JWMM.R215-02.

(C) CHI 2003 www.chijournal.org ISSN: 2292-6062 (Formerly in Practical Modeling of Urban Water Systems. ISBN: 0-9683681-7-4) 
if those points are routed to downstream inlets. Also, the limit on the scratch file size restricted the length of simulations and essentially prevented the use of other SWMM modules in this modeling exercise. Furthermore, the addition of water quality constituents significantly increases the size of the scratch files, further limiting the simulation period, which eventually was reduced to one year. Our resolution of these issues included reducing simulation periods and external processing using SAS.

The limitations decreased the efficiency of modeling with SWMM at these scales and have led us to begin a process to make improvements in SWMM to better facilitate the large-scale applications required to support current regulatory programs in the United States. Our goal is to improve SWMM to accommodate fully featured hydrology and water quality applications for watersheds at scales in excess of $10,000 \mathrm{mi}^{2}\left(25,000 \mathrm{~km}^{2}\right)$ using 5,000 to 10,000 RUNOFF sub-basins for simulation periods of $30 \mathrm{y}$ or more at 15 -min time steps.

\subsection{Background}

The Philadelphia Water Department's Office of Watersheds Source Water Protection Program initiated a comprehensive Source Water Assessment (SWA) project as a partnership with the Pennsylvania Department of Environmental Protection (PADEP) and water suppliers within the Schuylkill River and Delaware River watersheds in eastern Pennsylvania. The SWAs are intended to identify and prioritize potential sources of contaminants in the watersheds and to assess the susceptibility of the water supplies to the sources.

The SWA process was an extensive watershed-wide inventory of potential contaminant sources. Compilation of these sources was supported with GIS and database activities. The source database includes Resource Conservation Recovery Act (RCRA) and Comprehensive Environmental Response, Compensation, and Liability Act (CERCLA) facilities, Toxic Release Inventory (TRI) sites, Permit Compliance System (PCS) discharge sites, NPDES-permitted discharges, Above-ground Storage Tanks (ASTs), and other potential sources of contamination identified by water supply partners in the regions. The inventory also includes estimates of nonpoint sources and runoff point sources. The susceptibility analysis employed the database in a process of successive screenings to focus on those sources that have the greatest potential to affect water quality at the intakes. The screening and evaluation method used for most of the analysis relied on an innovative matrix-based, multi-criteria evaluation 


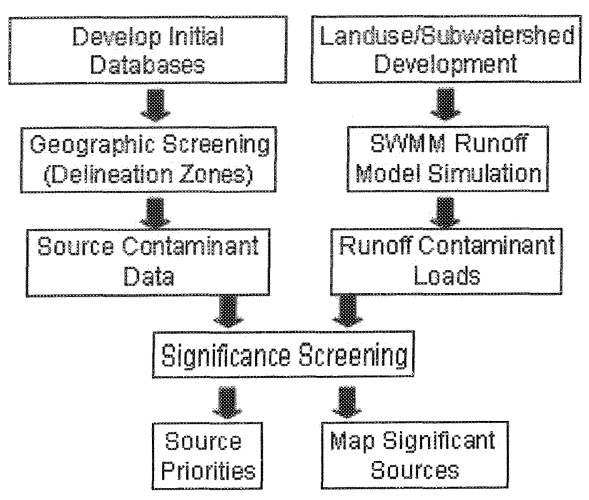

Figure 2.1 Source prioritization flow diagram.

program (EVAMIX). A schematic of the screening process is shown in Figure 2.1 and a more complete description of the overall SWA project is provided by Maimone and Crocket (2002).

The need to provide estimates of potential nonpoint source and runoff point source contaminant loads from a combined drainage area of the two watersheds over $11,500 \mathrm{mi}^{2}\left(30,000 \mathrm{~km}^{2}\right)$ presented one of the more difficult challenges faced in the execution of the SWA project. To meet this challenge, comprehensive, basin-wide, long-term continuous simulation models of watershed hydrology and water quality loading were applied. SWMM provided the flexibility to estimate runoff water quality pollutant loads by landuse category, by subwatershed, by larger-delineated watersheds, and over the entire study area. Also, SWMM allows real-time simulation of events which account for soil moisture conditions. The use of a complex deterministic model that attempts to represent realistically rainfall-runoff, groundwater, and water quality contaminant contributions at this scale is thought to be unique among the SWAs being performed across the United States today.

\subsection{Schuylkill Runoff Loading Model Development}

SWMM RUNOFF simulates rainfall-runoff quantities and quality at specified inlet locations. Figure 2.2 displays the structure of the SWMMRUNOFF model. The model inputs sub-watershed parameters, rainfall time-series, climatological data, and event mean concentrations (EMCs) for the land use categories, and 
outputs annual and monthly pollutant loads for the length of the simulation period. The model incorporates infiltration, depression storage, and roughness to estimate runoff flow and ultimately, runoff pollutant quantities.

The amount of a particular pollutant reaching the receiving stream is dependent on the volume of surface runoff and the concentration of that constituent in the runoff. An EMC is the total mass load of a pollutant yielded from a site during a storm divided by the total runoff water volume discharged during the storm. EMCs are related to the constituent of interest and the land use type. For a sub-watershed, the surface runoff from a particular land use computed by SWMM RUNOFF, is multiplied by the EMC for that land use type to yield a loading rate.

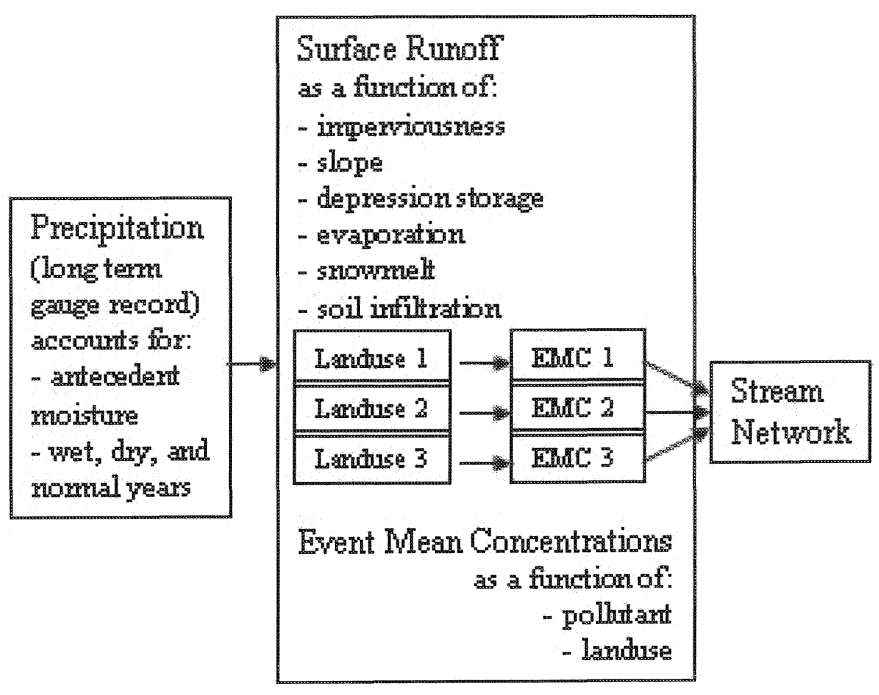

Figure 2.2 Watershed loading model schematic diagram.

\subsubsection{Subcatchments}

The subcatchments of the Schuylkill River Watershed ultimately drain into the Delaware River Basin. The Schuylkill Watershed is composed of 356 subwatersheds (Figure 2.3) which were further divided into land use categories to track the contributing pollutant loads from each land use category. The intersection of the 356 sub-basins with 14 potential land use types in each subbasin resulted in almost 4000 sub-basin model units. 


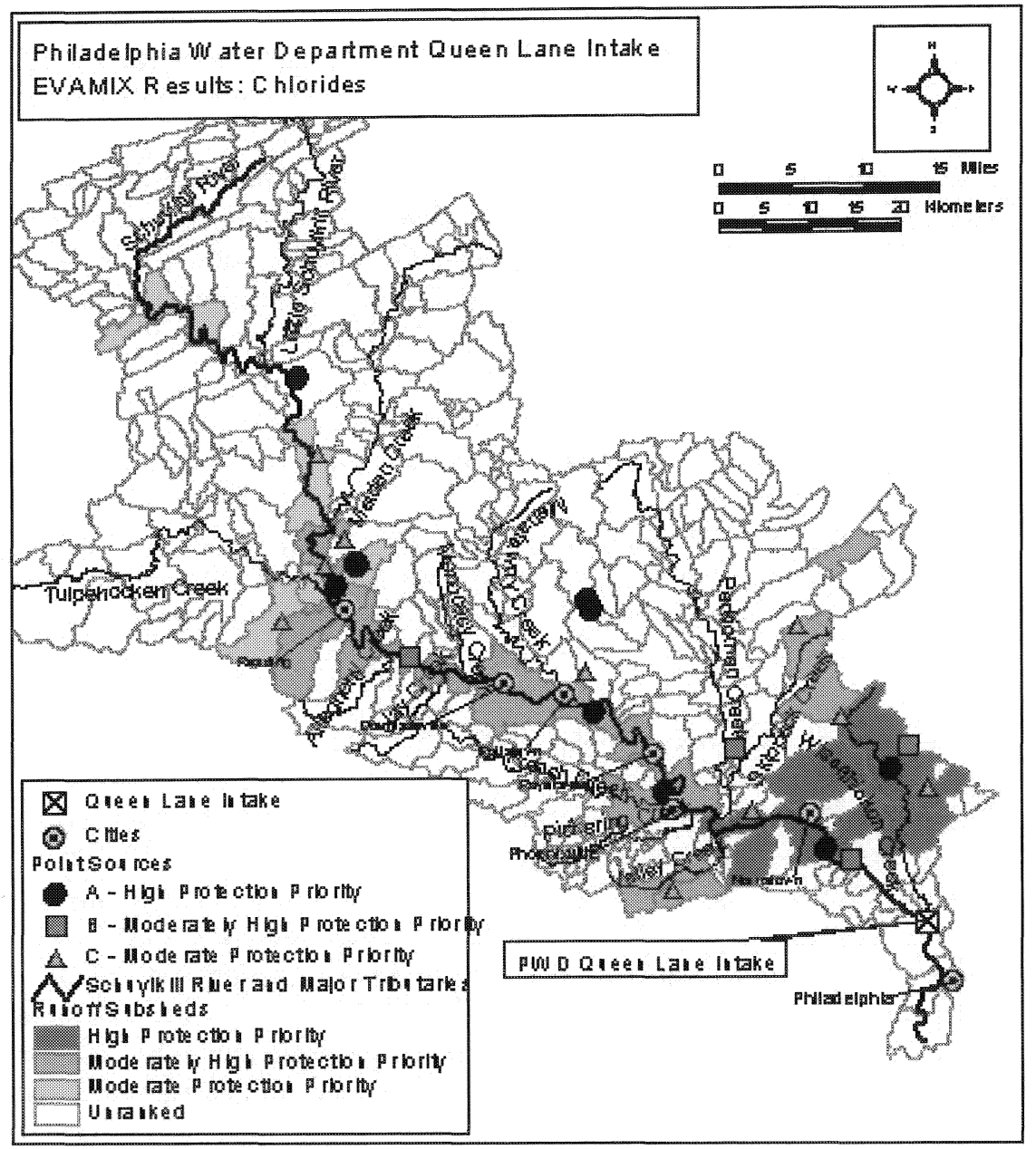

Figure 2.3 Schuylkill Runoff Model sub-watersheds.

The land use categories were based on the USGS's National Land Cover Dataset (NLCD) updated with 2000 Census data for residential and commercial areas. The land use categories distinguish the amount of rainfall that runs off the surface of the sub-watershed, as opposed to infiltrating into the subsurface or entering the atmosphere through evapotranspiration. For example, during a storm, more rainfall becomes surface runoff in a residential area than in a forested area, since there are more impervious surfaces such as driveways, roads, and buildings in developed areas. The forested area retains more of the 
rainfall, which either infiltrates into the ground or evaporates. For modeling purposes, the land use categories were summed for each sub-watershed in order to track individual land use loading contributions to the totals for each subwatershed.

The percentage of impervious area for residential areas was calculated using Stankowski's methodology, which calculates the percentage of total impervious area as a function of the population density. For pervious areas, the portion of precipitation that runs off is affected by slope, depression storage, infiltration, vegetative cover, and evapotranspiration. Infiltration is determined primarily by the type of soil. The SWMM RUNOFF model simulates infiltration using the Green-Ampt theory for both saturated and unsaturated soils. The Green-Ampt infiltration routine relates infiltration rate to the soil-water conditions of the surface and the total volume of rainfall infiltrated. For the Schuylkill RUNOFF model, the soil information was downloaded from the Natural Resources Conservation Service (NRCS) and the soils GIS coverage was intersected with sub-watersheds to identify the soil types in each subwatershed.

\subsubsection{Event Mean Concentrations (EMCs)}

EMCs were collected from a various sources and selected on the applicability to the study areas. Applying EMCs to calculated runoff volumes provided reasonable estimates of runoff pollutant loadings. EMCs for the soluble pollutant categories were assigned according to the land use category. The SWMM RUNOFF module allows the model to assume a constant concentration of a constituent for the duration of the storm event. The quantity of a constituent in surface runoff is a function of constant EMCs associated with the land use categories. The RUNOFF model water quality parameters included cryptosporidium, total organic carbons (TOCs), metals and heavy metals, nitrates, phosphorus, petroleum hydrocarbons, chlorides, total suspended solids (TSS), and total/fecal coliform.

Runoff volumes are computed for each land use category based on the percent imperviousness of the land use, annual rainfall, slope of the subwatershed, evaporation, infiltration, and depression storage. This analysis was performed on a sub-watershed by sub-watershed basis, and the results were used to determine load distributions according to the land use category. The pollutant mass load estimate is computed for each land use within each subwatershed as a product of the EMC and the surface runoff. By estimating the pollutant loading over the area of a land use type within a sub-watershed and 
summing for all land uses for the sub-watershed, the total pollutant load from a sub-watershed can be computed.

\subsubsection{Meteorological Data}

The amount of surface runoff is primarily driven by the precipitation. Longterm climate and precipitation records were used to drive the hydrology of the system. Using a long-term record represents a wide range of hydrologic conditions that occur in a given climate. Using a long-term record on a continuous basis accounts for antecedent moisture conditions and more accurately represents initial conditions at the beginnings of storm events. Snowfall and snowmelt affect the quantity and timing of surface runoff during the winter months and have been included in the long-term continuous simulation.

If available, rainfall, wind, and temperature data for a period of $10-\mathrm{y}$ (1990-1999) were collected for RUNOFF model simulations. The hourly rainfall data were obtained from the National Weather Service (NWS) at stations in and around the Schuylkill Watershed. The hourly data was broken into 15minute increments utilizing RAINMASTER. To account for snowmelt, the daily minimum and maximum temperatures and average monthly wind speeds were obtained for the period of simulation.

\subsubsection{Model Calibration}

In order to assess the reliability of the pollutant loads from SWMM, a hydrograph separation analysis was conducted to compare base loading with runoff quantities and water quality loads from SWMM. A hydrograph separation program was created in SAS(r) to divide the total flow into baseflow and surface runoff. This program was modeled after the USGS's HYSEP computer program, and uses the sliding-interval method to perform the separation. The hydrograph separation yields total flow, baseflow, and runoff values in daily, monthly, seasonal, and annual averages. The daily average flows were obtained from the USGS for gauges located in the Schuylkill River Basin.

The sliding-interval method associates a baseflow with a selected day by taking an equal interval before and after that day and assigning the lowest discharge to that day. The intervals are calculated based on the drainage area. For example, as shown in Figure 2.4, the drainage area for the USGS gauge located in the Perkiomen Creek at Graterford has a drainage area of $279 \mathrm{mi}^{2}$ $\left(722 \mathrm{~km}^{2}\right)$. The interval after surface runoff is $3.1 \mathrm{~d}$. The interval for finding 


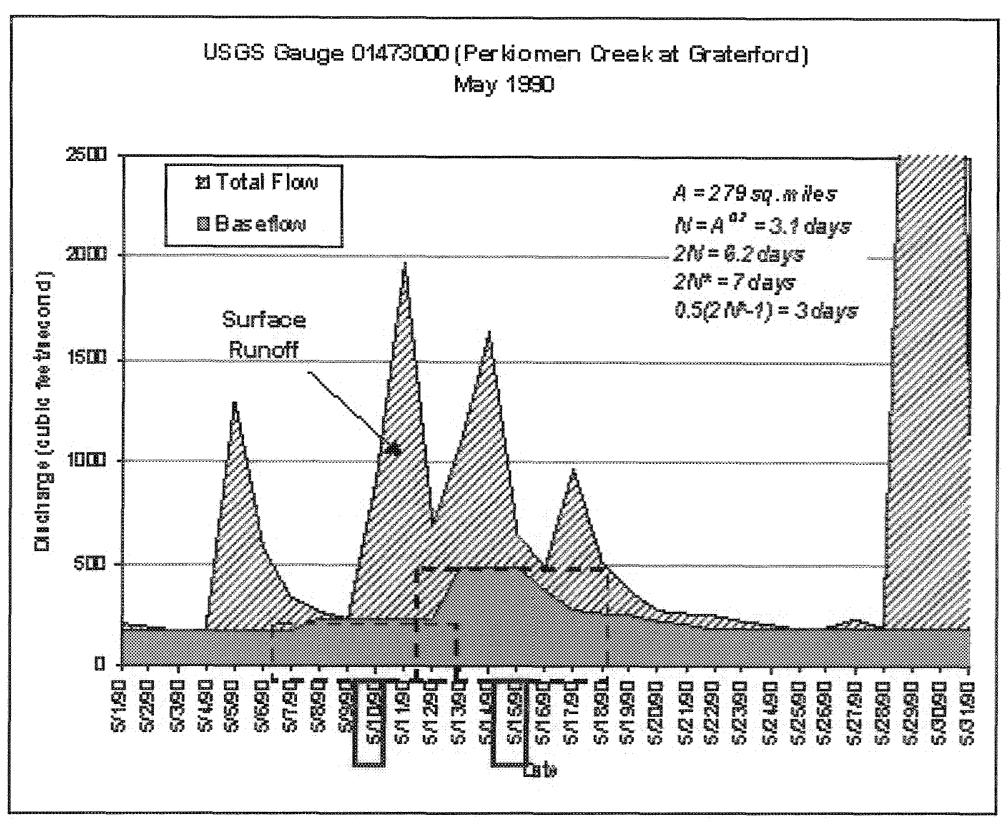

Figure 2.4 Hydrograph separation analysis for the Perkiomen Creek at Graterford for May 1990.

the baseflow is applied before and after a specified day. Thus, total duration is twice the calculated interval $(6.2 \mathrm{~d})$ and then rounded to the nearest odd number greater than that value ( $7 \mathrm{~d}$ ) to include the interval before and after and that day as well. Three is the minimum duration used in the sliding interval method. The selected day should be the median with equal durations before and after to associate the lowest discharge in the entire interval. For the Perkiomen Creek at Graterford, the total interval is $7 \mathrm{~d}$ and the interval for May 10,1990 and May 15, 1990 are displayed in Figure 3.3. The baseflow designated to March 10, 1990 is $232 \mathrm{cfs}\left(6.57 \mathrm{~m}^{3} / \mathrm{s}\right)$ and March 15,1990 is $484 \mathrm{cfs}\left(13.7 \mathrm{~m}^{3} / \mathrm{s}\right)$.

The surface runoff is the difference between the total streamflow and the baseflow, as described above. In Figure 2.4, the baseflow is the lighter gray area and the darker, diagonally-patterned area is the remainder of the total flow that is designated as surface runoff.

The hydrograph separation was conducted for the active USGS gauges in the Schuylkill Watershed. The values are average annual flows in $\mathrm{cfs}$ and in/y for the period of record available for each gauge. The \% runoff is the amount of total flow that is assumed to be surface runoff. The total flow, baseflow, and 
runoff values were converted to in/y by dividing the flows by the drainage area. The average annual runoff is $7.7 \mathrm{in} / \mathrm{y}(196 \mathrm{~mm} / \mathrm{y})$. The USGS streamflow hydrograph separation results were used to calibrate SWMM. Comparing the computed values with the hydrograph separation results, parameters in SWMM were further refined.

\subsection{Results}

\subsubsection{Model Output}

SWMM was used to quantify contaminant loads for nine pollutant categories included in the susceptibility analysis. Generally, the greater contaminant loads are found in the lower portion of the watershed. These areas tend to have more development, and thus greater impervious surfaces and runoff volumes. Figure 2.5 is an example that shows the results for the watershed for TSS. The darker areas, representing higher load estimates, are with agricultural areas or developed areas in the watershed. The lighter areas are either generally less developed or have little agricultural land and hence, have less TSS loads from rainfall-runoff. Similar graphics were created for each of the nine contaminant categories. Table 2.1 displays the average annual contaminant loads by major sub-watershed ordered upstream to downstream.

The contaminant loading results for the Schuylkill Watershed are summarized as follows:

- Cryptosporidium: The concentrated areas of highest pollutant estimates were located in the Middle Schuylkill and the lower portion of the Upper Schuylkill, through which the mainstem Schuylkill River flows. The Perkiomen watershed also had high estimates of cryptosporidium loads from runoff. The lower portion of the Maiden Creek rendered high daily loads per area because over $30 \%$ of these sub-watershed areas are characterized as pasture or hay, which have the highest EMC for cryptosporidium.

- Disinfection By-product Precursors (TOCs): The higher EMCs for disinfection by-products were associated with developed land use categories such as commercial/industrial/transportation, residential, and mining. The concentrated areas of highest pollutant estimates were located in the Lower Schuylkill and the lowerportion of the Middle Schuylkill. The lower Upper Schuylkill, 


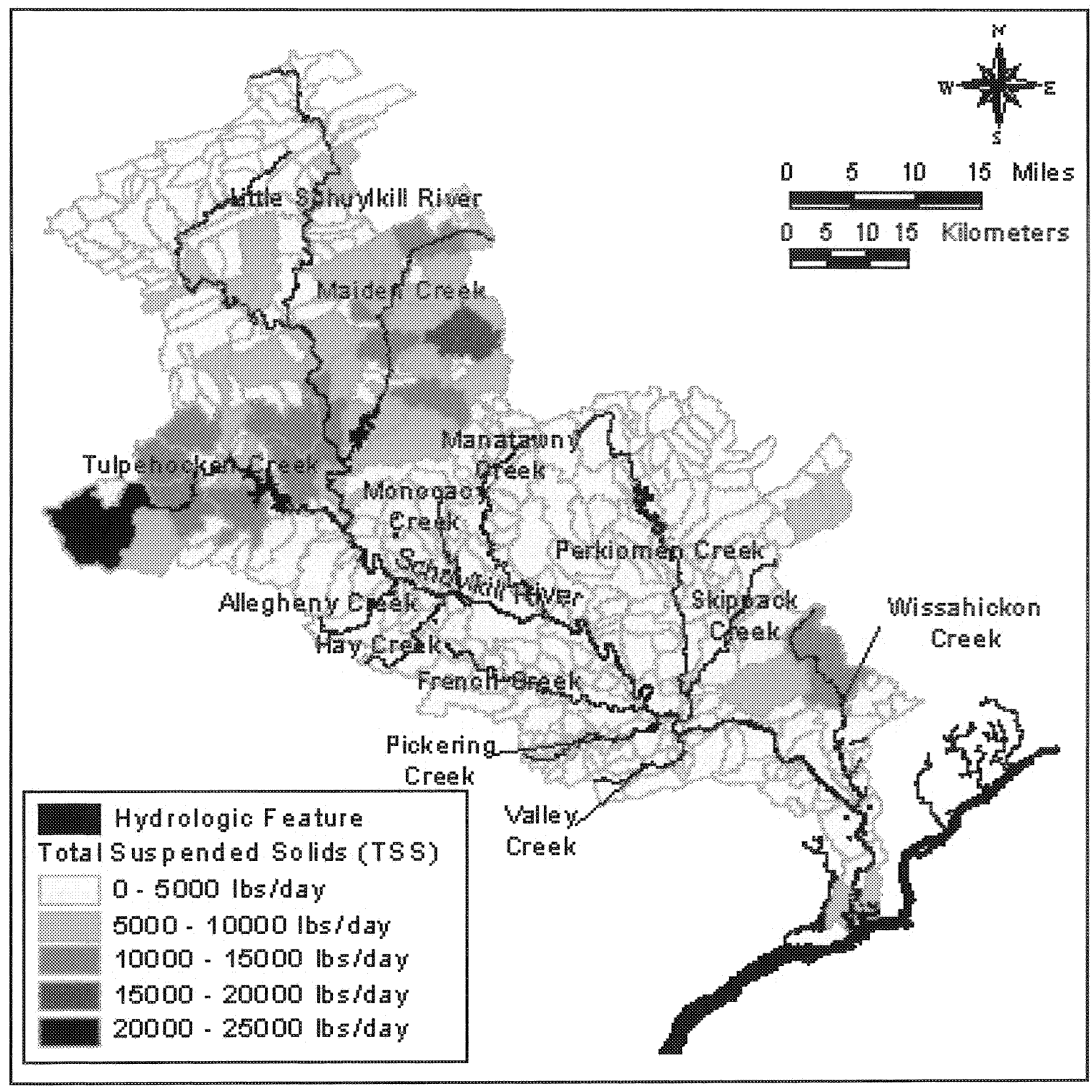

Figure 2.5 Example of Schuylkill Runoff Loading Model results.

the upstream portion of the Middle Schuylkill, and the Perkiomen watersheds also had high estimates of disinfection by-product loads from runoff.

- Metals/Heavy Metals (Lead): The concentrated areas of highest pollutant estimates were located in the Lower Schuylkill and the lower portion of the Middle Schuylkill, the more developed areas. The upstream portions of the Middle Schuylkill also had high estimates of metals/heavy metals from runoff. Besides the expected area in the Lower Schuylkill near Philadelphia, the sub-watersheds in the Middle Schuylkill near Reading, a relatively developed area, exhibited high estimates of metals/heavy metals according to the computed results. 
Table 2.1 Computed contaminant loading by major sub-watershed.

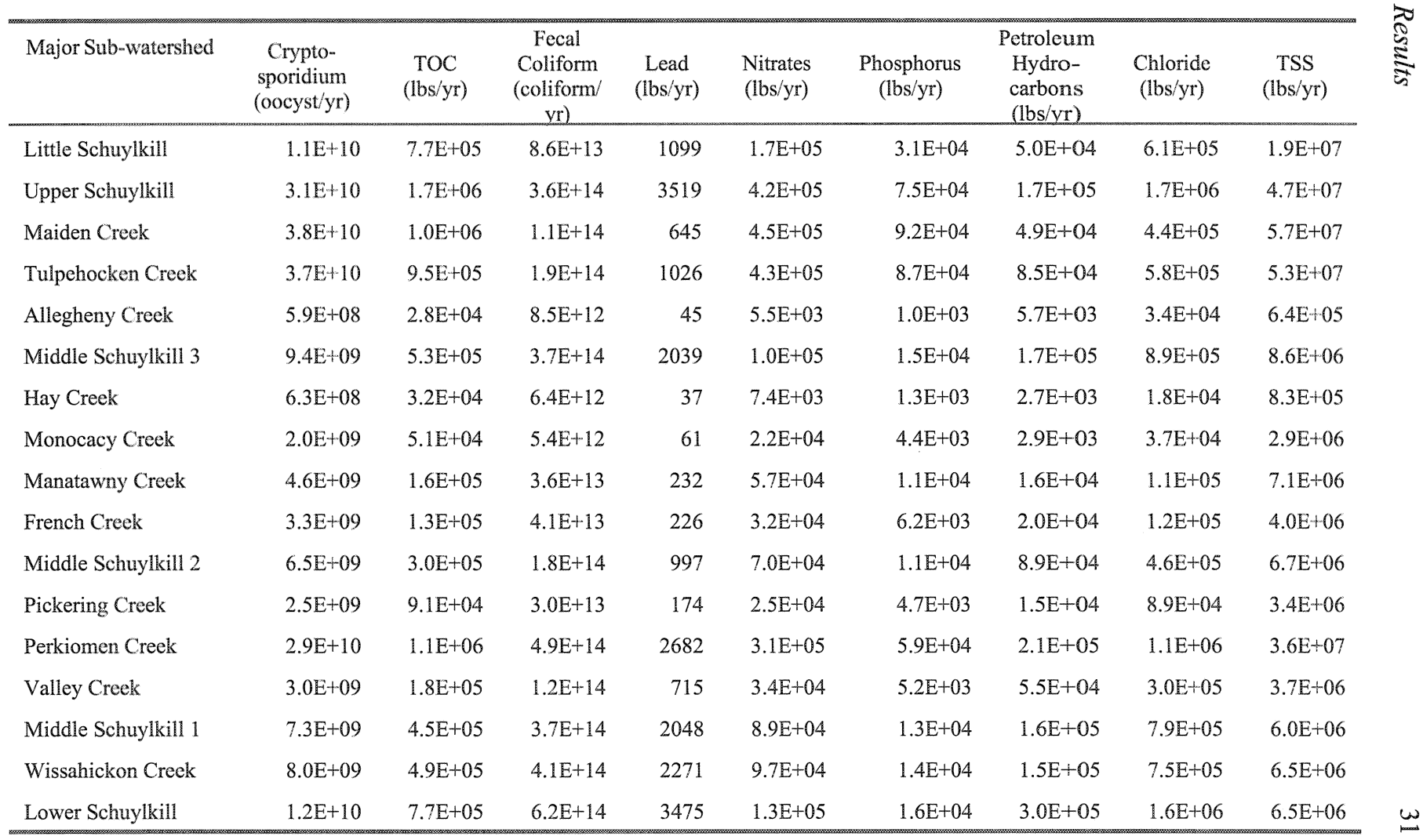


- Conservative Nutrients (Nitrates): The highest EMCs for conservative nutrients were associated with residential land use categories, followed by commercial/industrial/transportation, then mining. The concentrated areas of highest pollutant estimates were located in the Lower and Middle Schuylkill, where much of the area is designated as developed. The lower part of the Upper Schuylkill and Perkiomen watersheds also had high estimates of conservative nutrients loads from runoff.

- Non-conservative Nutrients (Phosphorus): The higher EMCs for non-conservative nutrients were associated with developed land use categories such as commercial/ industrial/transportation, residential, and mining. The concentrated areas of highest pollutant estimates were located in the Lower Schuylkill and the lower portion of the Middle Schuylkill. The upstream portions of the Middle Schuylkill also had high estimates of non-conservative nutrients from runoff. Besides the expected area in the Lower Schuylkill near Philadelphia, the sub-watersheds in the Middle Schuylkill near Reading, a relatively developed area, exhibited high estimates of non-conservative nutrients according to the computed results.

- Petroleum Hydrocarbons: The highest EMCs for petroleum hydrocarbons were associated with commercial/industrial/transportation areas, followed by residential land use categories. The concentrated areas of highest pollutant estimates were located in the Lower Schuylkill and the lower portion of the Middle Schuylkill. The upstream portions of the Middle Schuylkill also had high estimates of petroleum hydrocarbons from runoff. Besides the expected area in the Lower Schuylkill near Philadelphia, the sub-watersheds in the Middle Schuylkill near Reading, a relatively developed area, exhibited high estimates of petroleum hydrocarbons according to the computed results.

- Salts (Chlorides): The higher EMCs for disinfection by-products were associated with developed land use categories such as commercial/industrial/transportation, mining, and residential, listed in decreasing order. The concentrated areas of highest pollutant estimates were located in the Middle Schuylkill and Lower Schuylkill. The upstream portion of the Middle Schuylkill watershed and the lower part of the Perkiomen watershed also had high estimates of salt loads from runoff. 
- Turbidity (TSS): The highest EMCs for turbidity were associated with agricultural and forested areas, followed by wetlands, then residential land use categories. The concentrated areas of highest pollutant estimates were located in the Lower and Middle Schuylkill Watersheds. The lower portion of the Upper Schuylkill, the Maiden, and the Perkiomen watersheds also had high estimates of turbidity loads from runoff. Although the EMCs for forested and agricultural lands were higher than for developed areas, since they are less impervious these areas rendered less surface runoff.

- Total/Fecal Coliform: Generally, the concentrated areas of highest pollutant estimates were located in the Lower Schuylkill and the lower portion of the Middle Schuylkill, the more developed and impervious areas. The lower area of the Upper Schuylkill, the upstream portion of the Middle Schuylkill, and the Perkiomen watersheds also had high estimates of total/fecal coliform loads from runoff. The daily pollutant per area values also showed the Middle Schuylkill with predominantly large total/fecal coliform loads per acre.

\subsubsection{EVAMIX Results}

EVAMIX output was used to complete the screening by ranking the sites in descending order of importance and then selecting the top sites based on the results of the ranking. EVAMIX was used to rank all sources over the entire range of contaminant categories. Full ranking allowed us to compile a final list of sources, independent of contaminant class. Ranking by contaminant category was completed using six criteria and the multi-criteria evaluation program EVAMIX. Results from each of the contaminant categories based evaluations resulted in a listing of high, medium, and low priority sites for that contaminant category. The screening and ranking process successively selected the most important sites for each source type and combined them in an organized manner to produce a final list of high priority sites. The process provided the top sites from each source category, and provides valuable insight into the relative importance of each source type. Enough sites were included from each category to ensure that no highly ranked sites would be overlooked.

The results discussed below are based on the most downstream intakes in the Schuylkill. Figure 2.6 maps the site locations for point sources and subwatersheds in the Lower Schuylkill Watershed that scored highest in the 
ranking process for the PWD Belmont Drinking Water Intake. The numbers indicated on the map correspond to identification numbers of the various sources in the tables.

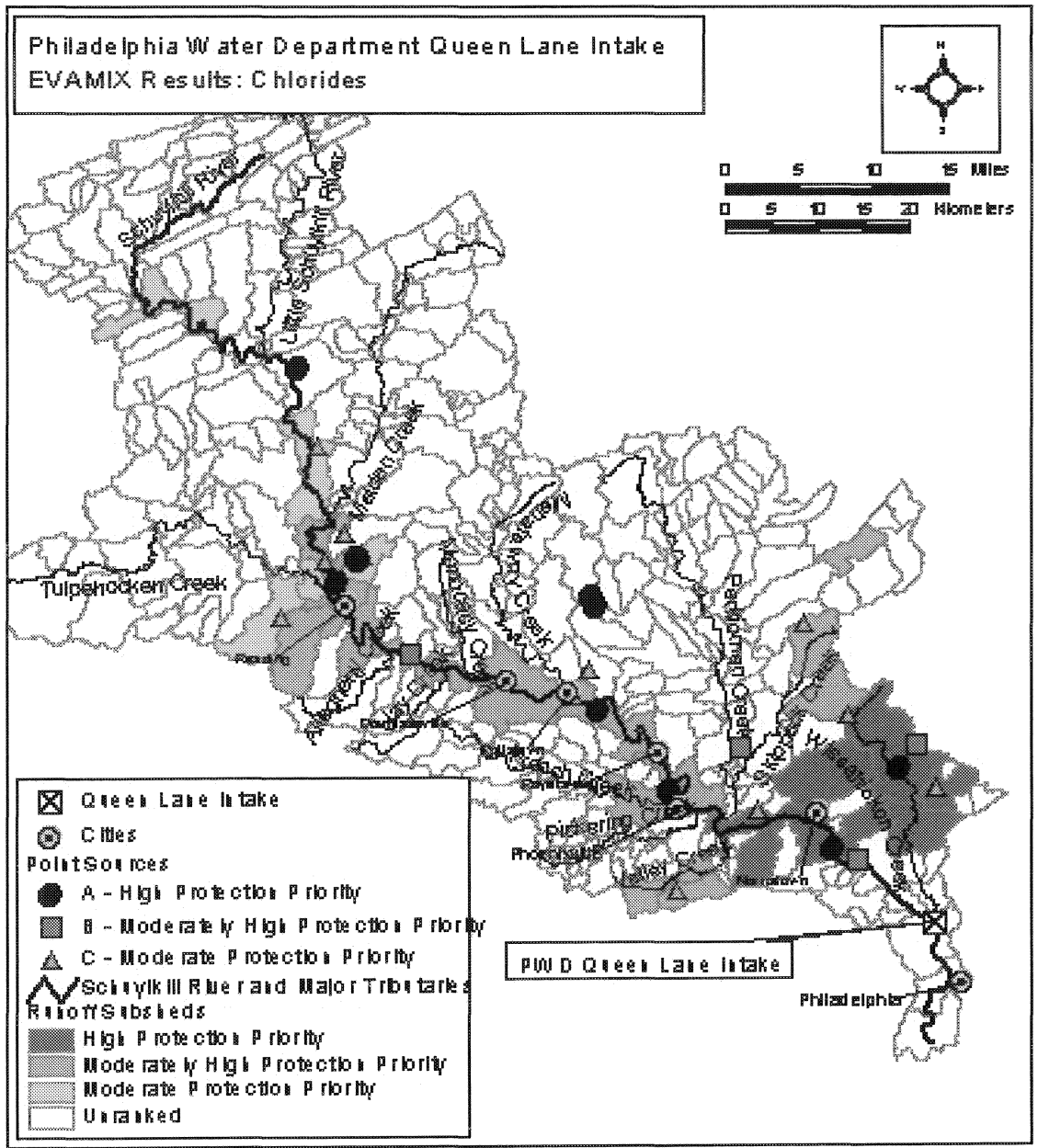

Figure 2.6 Priority point sources and sub-watersheds for PWD's Belmont Intake in the Lower Schuylkill watershed.

The results provided significant insight into the relative threat that various types of sources might have on the water quality at the intake. The key results are: 
- All the highest ranked sites were either NPDES sites from the PCS database or stormwater pollutant loading represented by various sub-watersheds.

- Stormwater or nonpoint source loading appeared to also represent a high priority.

- TRI sites were generally ranked lower. All TRI sites were found to be in the "moderate" priority category.

- RCRA sites, with or without ASTs, were generally ranked the lowest of all of the types of sites. Very few were found in the combined top priority category for the Schuylkill River Watershed.

- Results indicated that with a balanced assessment, those contaminant sources that are discharging to the river (NPDES permitted point sources or stormwater runoff) represented the greatest concern. Those with only the potential to release contaminants through spills or leaks (TRI, RCRA, AST) were generally given a lower priority.

- Despite the low overall rankings, the highest potential relative impacts appeared to occur with the TRI and AST sites. The relative impact numbers showed that, were a catastrophic spill or leak to occur at these highly ranked sites, concentrations at the intake could potentially be very high.

- Health Impacts, as scored in the assessment, had a large influence on the resulting rankings, with those sites ranked high on potential health impacts ranking as important sites.

- Treatment Impacts were also important in the final rankings, with those sites scoring high on potential impact to the treatment process also ended up highly ranked in the overall assessment.

- The geographic distribution of significant sources showed that most of the high protection priority sources for the most downstream SWAP intake in each of the watersheds were point sources from nearby drainage areas of the Wissahickon Creek and Schuylkill River below Valley Forge in the Schuylkill Watershed.

- A comparison of the types of sources indicated by the ranking process with the sources indicated by water quality analysis and impaired stream information confirmed that NPDES discharges and polluted runoff (non-point sources) from developed areas were the most important influences on water quality at the two most downstream SWAP intakes in each of the watersheds. 
The following are overall observations of the contaminant category results for the most downstream intakes in each of the watersheds:

\section{Salts}

The highest priority sources of chlorides were either stormwater runoff from urbanized watersheds, or potential releases of industrial salts from industrial sites as represented by sites listed in the TRI database. It should be noted that neither type of source individually appeared to provide sufficient loading to cause water quality impairments at the intake, but when combined, especially during winter periods, the runoff may result in some impacts.

\section{Cryptosporidium}

Sources of pathogens were either stormwater runoff from agricultural or urbanized watersheds, and permitted discharges from wastewater treatment plants. NPDES sources were represented in the high priority category, while nonpoint sources were in the lower category. Most sources appeared to be relatively minor contributors. However, there were some sources that could provide sufficient loads to have a cumulative impact on the water quality. The overflows of raw sewage during wet weather events were roughly estimated and compared to the other potentially significant sources.

\section{Fecal Coliform}

Sources were either stormwater runoff from agricultural or urbanized watersheds, and permitted discharges from wastewater treatment plants. Although both sources were represented in the high priority category, the results suggest that periodic loading from stormwater was orders of magnitude higher than the loading from wastewater treatment plants. During dry weather flows, wastewater loading is insignificant at an intake, but during storm events, fecal coliform would be expected to increase by orders of magnitude. The overflows of raw sewage during wet weather events were roughly estimated and compared to the other potentially significant sources. There was a broad geographic distribution of potentially significant sources of fecal coliforms in the watershed. This may be because die-off was not factored into the analysis.

\section{Metals}

Results generally show that NPDES permitted discharges were the primary sources. Some TRI sites with significant storage or use of metals were also rated as high priority sources, primarily because a catastrophic leak or spill 
would result in extremely high concentrations. Non-point sources from urbanized watersheds were generally a medium priority. Most of the TRI and AST sites fall into the moderate protection priority category. However, it is important to note that acid mine drainage could not be included in this analysis and may be a more significant source than any of the other source categories

\section{Nitrates}

The high priority category was dominated by NPDES dischargers, primarily wastewater treatment plants. Most of the loading from these sites appeared to be relatively low, and was not likely to cause a cumulative impact that would cause an exceedance of the nitrate standard at the intake. Moderate priority sites were a mixture of NPDES sites, TRI sites, and non-point runoff from storm water. The potentially significant sources were located throughout the watershed. Therefore, watershed wide efforts to reduce nitrate impacts will be necessary.

\section{Petroleum Hydrocarbons}

There were a limited number of significant sources of petroleum hydrocarbons. Only above-ground storage tanks containing fuel, or stormwater runoff were identified as significant potential sources of petroleum hydrocarbon loading. Most of the high priority sites were either fuel storage facilities (with a low probability of release but potentially very high concentrations), or stormwater runoff with lower concentrations but frequent occurrence.

\section{Phosphorus}

Similar to nitrates, the high protection priority category was dominated by NPDES dischargers, primarily wastewater treatment plants. Most of the loading from these sites appeared to be relatively low, and was not likely to cause a cumulative impact that would cause significant water quality impairment at the intake. There are a few very large industrial sites that were also included in the high category, primarily due to the high potential concentrations should a spill occur. Moderate priority sites were mainly a mixture of TRI sites and nonpoint runoff from stormwater. A large majority of the potentially significant sources were located in the drainage areas along the mainstem Schuylkill River.

\section{Disinfection By-Product Precursors (Total Organic Carbon)}

Total organic carbon (TOC) was used as an indicator of disinfection byproduct precursors. Overall the high protection priority sites were NPDES 
discharges from wastewater treatment plants. In general, NPS sites appeared to have a lower total load and impact on water quality than do the NPDES sites. TRI and AST sites were all found in the low priority category.

\section{Turbidity (Total Suspended Solids)}

Turbidity was analyzed using total suspended solids (TSS) as a surrogate. Only stormwater runoff and NPDES discharges were identified as potentially significant sources of TSS. The stormwater runoff tended to show much higher loading with less frequency. The NPDES sites had lower rates of TSS loading, however, they were more constant discharges. Loading rates from non-point sources appeared high enough to cause concern for cumulative impacts at the intake during storm events.

\subsection{Technical Challenges}

The application of SWMM to a watershed of this scale revealed certain model limitations. Issues were realized throughout the model development, simulation, output, and calibration. These obstacles were resolved with either modifications to the SWMM code or post-processing the model output.

\subsubsection{Challenges for Model Input Data}

During the development of the model, limitations on array bounds of the input data prevented processing of the model. The model was limited to six subwatersheds to an inlet location. Also, SWMM inputs one default set of snowmelt line pairs (I1/I2 lines as defined in the SWMM documentation manual). However, when the model is run, SWMM generates one pair of snowmelt lines per sub-watershed. There is a limit set on the number of these pairs. The bounds set for the number of sub-basins entering an inlet point and the number of snowmelt lines corresponding to each sub-basin required modifications to the SWMM code. The SWMM code was adjusted to expand the array bounds for these components of the model.

\subsubsection{Challenges for Model Simulation and Output}

A number of restrictions were discovered during simulation of the model and attempting to obtain output from the model. One issue that arose during the modeling process was the two gigabyte limitation in the size of scratch files. The 
implication of the limit on the scratch file size was to limit the length of simulations and essentially prevent the use of other SWMM modules in this modeling exercise, requiring that all computations be performed either within the RUNOFF module or externally in SAS programs. Furthermore, the addition of water quality constituents significantly increases the size of the scratch files, further limiting the simulation period, which eventually was reduced to $1 \mathrm{y}$. Our desire to simulate $30 \mathrm{y}$ for this project required us to reduce the simulation to $10 \mathrm{y}$ and perform 10 individual runs (1 run per y) and to accumulate results and develop resultant long-term hydrologic and water quality estimations by accumulation externally to SWMM.

To retrieve average annual loads from RUNOFF, summary tables were included in the output file using the \# PRINT_ALL_INLETS command. This provided average annual loads for each sub-watershed in lbs/y and lbs/ac/y. However, since our model sub-basins were the Schuylkill sub-watersheds divided into each land use category, the output loads were for each landusesubwatersheds. Since SWMM does not have the capabilities to create summary tables for both the landuse-subwatersheds and the sub-watersheds, these tables were extracted from the SWMM output files and summed for each subwatershed using SAS. Post-processing using SAS allowed for quantifying the contaminant loads by land use type, sub-watershed, larger sub-watershed groupings, and the entire Schuylkill watershed.

\subsubsection{Challenges for Groundwater Simulation}

Understanding the dynamics of groundwater flow in SWMM also added challenges for the Schuylkill SWA. When comparing the model output with the results of baseflow separation, the issue of defining interflow arose. Figure 2.7 revisits the hydrograph separation example from Section 2.3.4 indicating the baseflow and interflow for the hydrograph separation method. For example, comparing the two datasets, total flow can be calculated as follows:

- Baseflow Separation Technique

Total Flow $=$ base flow + interflow/runoff

22 in. $=15$ in. +7 in. $(560 \mathrm{~mm}=380 \mathrm{~mm}+180 \mathrm{~mm})$

- SWMM Model with Groundwater Flow

Total flow $=$ baseflow/interflow + runoff

22 in. $=18 \mathrm{in.}+4 \mathrm{in.}(560 \mathrm{~mm}=460 \mathrm{~mm}+100 \mathrm{~mm})$ 
USGS Gauge 01473000 (Perkiom en Creek at Graterford) May 1990

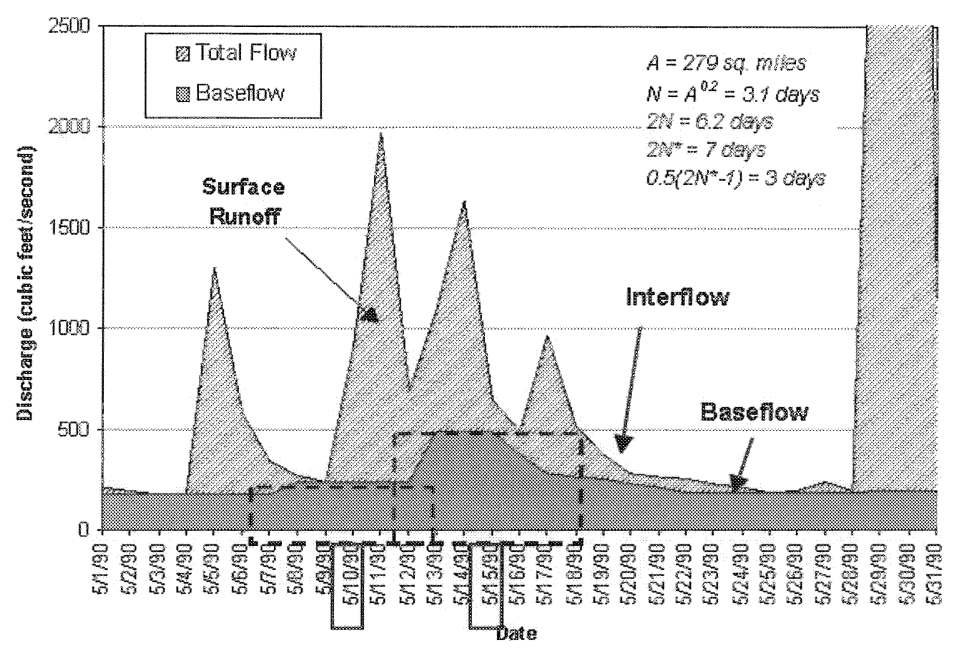

Figure 2.7 Components of the hydrograph separation.

For the same total flows, the hydrograph separation technique groups interflow with runoff while SWMM seems to group interflow with baseflow, yielding a difference in runoff of 3 inches $(\sim 80 \mathrm{~mm})$. The different representations of the groundwater is shown in Figure 2.8 The model flows showed a slower response of baseflow (months) and faster response of interflow (days).

The dynamics of the groundwater module of SWMM does not capture the intermediate response (days) after initial runoff ceases (hours). Also, maintaining minimum flows during dry periods by controlling the degree of water table movement and rate of groundwater discharge versus water stored may allow for more accurately modeling the groundwater component.

\subsubsection{Challenges for Model Calibration}

In addition to groundwater-related issues which arose for model calibration, other limitations of SWMM needed to be resolved. First, separate simulations were executed for calibration runs, since it was not necessary to model water quality loads while calibrating the runoff flows. Interface file size limitations were a factor in the decision to execute separate simulations. Also, SWMM did not allow retrieval of daily flows at selected inlet points, if those points are routed to inlets locations further downstream in the system. For example, if subshed 


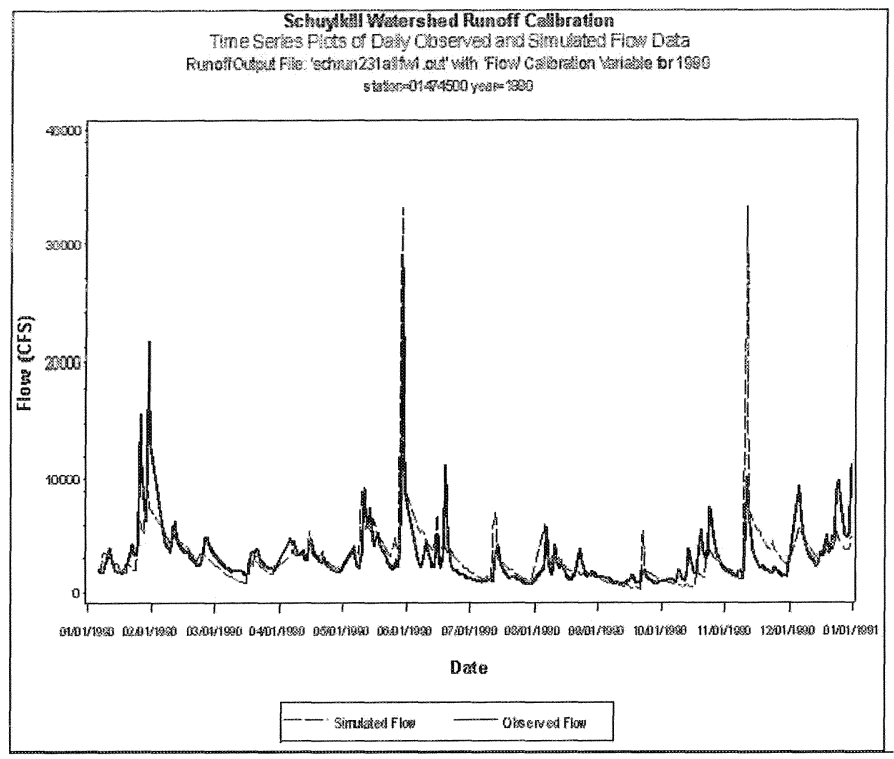

Figure 2.8 Observed and simulated runoff flows.

A were route to inlet $A$ and subshed $B$ to inlet $B$ as routed final destinations, SWMM would output flows at inlet A and B. However, if flows to inlet A are further routed in the model to inlet B, the SWMM would output flows only at inlet B. A SAS program was created to extract daily flows from the output file and sum flows from multiple locations externally.

\subsection{Conclusions}

A number of modifications and work-arounds were performed to apply SWMM for the SWAPs. However, the issues encountered during the modeling process revealed the issues that may needed to be considered for future use in large-scale watershed modeling. Moreover, the flexibility of SWMM did allow a number of external programs to be used in conjunction to post-process and display the computed runoffloading. Addressing the obstacles mentioned in this chapter may enhance SWMM's applications and capabilities.

The SWMM-generated estimates of runoff loads are used in the larger susceptibility analysis through routines developed in the database management system to route all potential sources of contamination relative to each drinking 
water intake throughout the watersheds. These runoff contaminant loadings for model areas were compared with contaminant estimates of point sources and prioritized based on the susceptibility and vulnerability of the contaminant categories at drinking water intakes throughout the Schuylkill and Delaware watersheds. Based on the results of the susceptibility analysis, water quality data, and stream impairments, it is clear that the impacts from stormwater runoff need to be addressed from the communities along the mainstem of the Schuylkill River from Reading to Philadelphia. The results of the SWAs provide future planning and targeting for the source waters in the Schuylkill as well as overall watershed planning initiatives.

Identification and prioritization of significant sources of pollutants is valuable, not only to the SWA process and the water suppliers in the basins, but also for use in the wide-scale, generalized watershed management planning efforts of the Philadelphia Water Department's Office of Watersheds. Experience to date confirms that the use of a comprehensive, complex watershed modeling system lends credibility to the robustness of the runoff pollutant estimates and is considered to be a key factor for a successful SWA program.

\section{References}

Federal Highway Administration. (1999) Pollutant Loadings and Impacts from Highway Stormwater Runoff, Volume III: Analytical Investigation and Research Report. Federal Highway Administration.

James, William, Wayne C. Huber, Robert E. Dickinson, and W. Robert C. James (1999) Water Systems Models: Hydrology, Users Guide to SWMM4 Runoff and Supporting Modules. Computational Hydraulics International, Guelph, Ontario, Canada.

Maimone, M., Crockett, C. (2002) Prioritization of Contaminant Sources for the Schuylkill River Source Water Assessment. Watershed 2002 Conference Proceedings, Water Environment Federation.

Smullen, J.T., Shallcross, A., Cave, K. (1999) Updating the U.S. Nationwide Urban Runoff Quality Database. IAWQ's Water Science and Technology, Vol.39, No.12.

Stankowski, S.J. (1975) Population Density as an Indicator of Urban and Suburban Land Surface Modification. USGS Professional Paper 800-b:B224. 